07

\title{
Влияние агрессивной среды на прерывистую деформацию алюминий-магниевого сплава АМг6
}

\author{
(C) А.А. Шибков, А.А. Денисов, А.Е. Золотов, С.С. Кочегаров \\ Тамбовский государственный университет им. Г.Р. Державина, \\ Тамбов, Россия \\ E-mail: Shibkov@tsu.tmb.ru
}

(Поступила в Редакцию 30 мая 2016 г.)

\begin{abstract}
Экспериментально установлено, что молекулярный (химический) процесс травления поверхности деформируемого алюминий-магниевого сплава АМг6 вызывает развитие макроскопического скачка пластической деформации амплитудой несколько процентов. С помощью численного моделирования процесса травления поликристаллического твердого тела показано, что в ходе травления морфология фронта коррозии меняется от евклидовой (плоской) к фрактальной (шероховатой). Полученные результаты свидетельствуют о ключевой роли состояния поверхности на развитие макроскопической механической неустойчивости материала, демонстрирующего эффект Портевена-Ле Шателье.
\end{abstract}

Работа выполнена при финансовой поддержке Российского научного фонда (проект № 15-12-00035).

DOI: 10.21883/FTT.2017.01.43957.224

\section{1. Введение}

Многие алюминиевые авиационные сплавы проявляют механическую неустойчивость, которая выражается в явлении прерывистого течения, известного как эффект Портевена-Ле Шателье (ПЛШ) [1]. Эффект ПЛШ связан с локализацией пластической деформации в полосах, которые ухудшают формуемость сплавов и могут вызвать внезапное разрушение как при металлообработке, так и в условиях эксплуатации. Вместе с тем, одним из важнейших факторов, влияющих на долговечность и живучесть авиационных алюминиевых сплавов, является коррозия под напряжением. Известно, что добавка магния увеличивает сопротивление коррозии этих сплавов [2]. Поэтому сплавы системы $\mathrm{Al}-\mathrm{Mg}$ обладают более высоким сопротивлением коррозии по сравнению с другими группами алюминиевых сплавов [3-6]. Механизмы коррозии под напряжением алюминий-магниевых сплавов, рассмотренные в работах [7-13], включают: а) механизм межкристаллитного растрескивания в результате селективного растворения вторичной $\beta\left(\mathrm{Al}_{3} \mathrm{Mg}_{2}\right)$-фазы, выделяющейся по границам зерен в сплавах с содержанием магния больше $3 \%$ [2] либо вследствие распространения трещин в зоне, обедненной магнием вдоль границ зерен $[14,15]$ или в результате водородного охрупчивания $[7,11,13,16,17]$; б) механизм транскристаллитного коррозионного растрескивания за счет, как предполагается, выноса ионов магния на поверхность сплава плоскими скоплениями дислокаций [18]. Последнее обусловлено увлечением примесных атомов движущимися дислокациями, т.е. явлением динамического деформационного старения (ДДС), которое ответственно также за развитие макроскопических неустойчивостей пластической деформации, таких как зуб текучести [18,19] и прерывистая деформация ПЛШ [20,21]. Поскольку ДДС характерно для сплавов системы $\mathrm{Al}-\mathrm{Mg}$ при комнатных и повышенных температурах, то следует ожидать связь между двумя явлениями: электрохимическим (коррозии под напряжением) и механическим (эффектом ПЛШ). Проблема осложняется тем обстоятельством, что полосы макролокализованной деформации, представляющие собой домены высокоскоростной интенсивной деформации, при взаимодействии с поверхностью могут вызвать множественные разрывы поверхностной окисной пленки, существенно ускорить локальную коррозию деформируемого сплава и вызвать его внезапное разрушение.

Проблема изучения взаимосвязи коррозии под напряжением и эффекта ПЛШ имеет по крайней мере две составляющие: а) исследование влияния агрессивной (корродирующей) среды на развитие пластических неустойчивостей ПЛШ; б) исследование влияния полосообразования, вызывающего прерывистую деформацию ПЛШ, на коррозию под напряжением. Настоящая работа относится к первой проблеме и посвящена исследованию влияния агрессивной среды на прерывистую деформацию промышленного алюминий-магниевого сплава АМг6, используемого при производстве авиационной техники и автомобилей.

Обычно экспериментальные исследования коррозии под напряжением алюминиевых сплавов проводят в средах, содержащих хлориды (во влажной атмосфере или в стандартном водном $3.5 \mathrm{wt} \%$ растворе $\mathrm{NaCl}[15,16]$ идр.). Образцы выдерживают под напряжением или очень медленно нагружают в течение десятков или сотен часов и исследуют изменения прочности, пластичности, коэффициента интенсивности напряжения $[15,16]$ и их корреляции с микроструктурными изменениями поверхности $[16,22]$. В данной работе в качестве агрессивной среды использовали $30 \mathrm{wt} \%$ раствор соляной кислоты, который активно реагирует с поверхностью сплава АМг6, так что время между моментом нанесения капли 
раствора на поверхность деформируемого образца и развитием в нем макроскопического скачка деформации, как обнаружено, не превышает $\sim 10 \mathrm{~s}$, что позволило для его изучения использовать комплекс быстродействующих in situ методов исследования деформации и полосообразования, разработанный в [23].

\section{2. Методика}

Методика приготовления и термообработки образцов изложена в работе [24]. Для регистрации и исследования деформационного и эмиссионного откликов на действие агрессивной среды использовалась горизонтальная мягкая испытательная машина, аналогичная описанной в [23]. Данная машина позволяет производить растяжения образцов с заданной скоростью возрастания напряжения $\dot{\sigma}_{0}=$ const и регистрировать одновременно скачки деформации с помощью триангуляционного лазерного датчика положения фирмы Riftec (чувствительность $1.5 \mu \mathrm{m}$ в полосе частот $0-2 \mathrm{kHz}$ ), скачки напряжения с помощью датчика усилия фирмы Zemic P3-C3-100 kg-3В (чувствительность $1.5 \mu \mathrm{V} / \mathrm{N}$ в полосе $0-2 \mathrm{kHz}$ ). Для мониторинга деформационных полос или трещин использовалась высокоскоростная цифровая видеокамера VS-FAST/G6 НПК „Видеоскан“ со скоростью до $1000 \mathrm{frames} / \mathrm{s}$ синхронно с регистрацией и измерением эмиссионных сигналов в результате локального воздействия агрессивной среды на плоскую поверхность деформируемого образца сплава АМг6 с размерами рабочей части $6 \times 3 \times 0.7 \mathrm{~mm}$.

Неустойчивая динамика фазовой границы и скачкообразная пластическая деформация сопровождается, как известно, эмиссионными явлениями, в частности, акустической [25-30] и в ряде случаев электромагнитной эмиссией $[31,32]$. Для регистрации сигналов акустической эмиссии (АЭ) в ходе травления поверхности и последующей прерывистой деформации использовали низкочастотный, в полосе частот $1 \mathrm{~Hz}-20 \mathrm{kHz}$, акустический датчик (вибропреобразователь) АР 34 (ООО „ГлобалТест“), который укрепляли через стеклянную пластину и слой масла на нижней неподвижной лопатке образца, связанной с базой (станиной испытательной машины). Плоскопараллельная стеклянная пластина необходима для обеспечения акустического контакта и электрической изоляции акустического датчика от образца. Выбор низкочастотного датчика определялся характерными временами в эволюции деформационных полос ПЛШ, известными из литературы: длительностью наиболее быстрой начальной фазы развития полос, $0.2-1.0 \mathrm{~ms}[33,34]$, и временем распространения полос $\sim 0.01-0.1 \mathrm{~s}[29,30,35,36]$. В качестве агрессивной среды использовался $30 \mathrm{wt}$ \% реагирующий с алюминием в соответствии с реакцией: $2 \mathrm{Al}+6 \mathrm{HCl} \rightarrow 2 \mathrm{AlCl}_{3}+3 \mathrm{H}_{2}$. В ходе деформирования на поверхность образца наносили каплю раствора соляной кислоты и исследовали связь между деформационным, силовым и акустическими откликами. Микроструктурные исследования проводили с помощью электронного зондового микроскопа di Innova SPM.

\section{3. Результаты и обсуждение}

3.1. Экспериментальные результаты. Типичная ступенчатая кривая растяжения с постоянной скоростью возрастания напряжения алюминий-магниевого сплава представлена на рис. 1. Видно, что с ростом приложенного напряжения растет амплитуда $\Delta \varepsilon$ скачков деформации и плато $\Delta \sigma$ между скачками (ступенями на деформационной кривой). Зависимость прироста напряжения $\Delta \sigma$ между скачками (плато на кривой нагружения) от амплитуды $\Delta \varepsilon$ предыдущего скачка деформации (ступени на кривой нагружения) можно приближенно аппроксимировать степенной зависимостью

$$
\Delta \sigma=A \Delta \varepsilon^{n},
$$

где константы $A$ и $n$ зависят от марки сплава и температуры испытания и скорости нагружения. Для сплава АМг6, деформируемого при комнатной температуре со скоростью $\dot{\sigma}_{0}=0.3 \mathrm{MPa} / \mathrm{s}, A=45 \mathrm{MPa}, n=0.273$.

Зависимость $\Delta \sigma(\Delta \varepsilon)$ позволяет в ходе деформирования предсказывать момент появления очередного макроскачка деформации и его амплитуду. Экспериментально установлено, что последняя треть плато наиболее уязвима по отношению к внешним воздействиям, в частности действию агрессивной среды на поверхность деформируемого образца. Например, нанесение капли 30 wt.\%-го раствора $\mathrm{HCl}$ на поверхность плоского образца в данном интервале плато (измеренного в отсутствие внешних воздействий) провоцирует генерирование сложной пространственно-временно́й структуры полос макролокализованной деформации, развитие деформационной ступени и генерирование характерных сигналов АЭ. Эти сигналы могут служить эмиссионными предвестниками и индикаторами развития макроскопических неустойчивостей, вызванных локальным действием агрессивной среды на поверхности нагруженного образца.

На первом этапе исследовали сигнал АЭ, генерируемый после нанесения капли $30 \mathrm{wt} . \%$-го раствора соляной

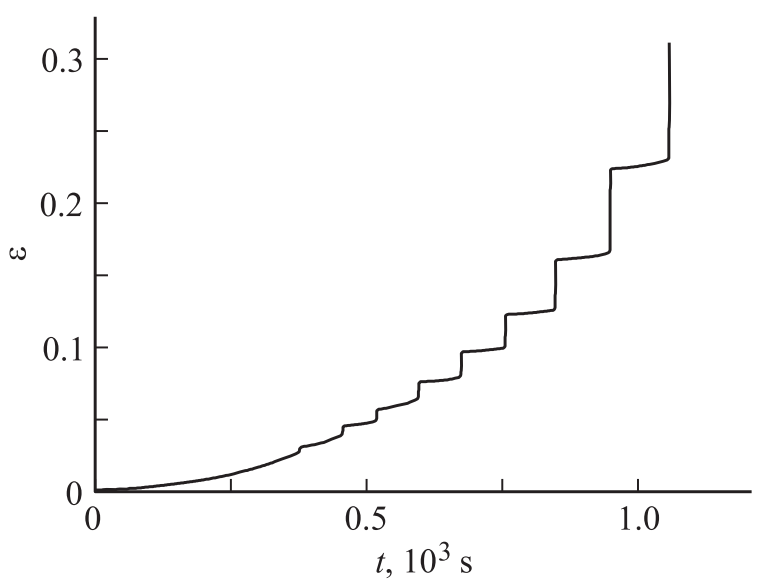

Рис. 1. Ступенчатая кривая растяжения сплава АМг6 в мягкой деформационной машине с постоянной скоростью роста напряжения. $\dot{\sigma}_{0}=0.3 \mathrm{MPa} / \mathrm{s}, T=300 \mathrm{~K}$. 


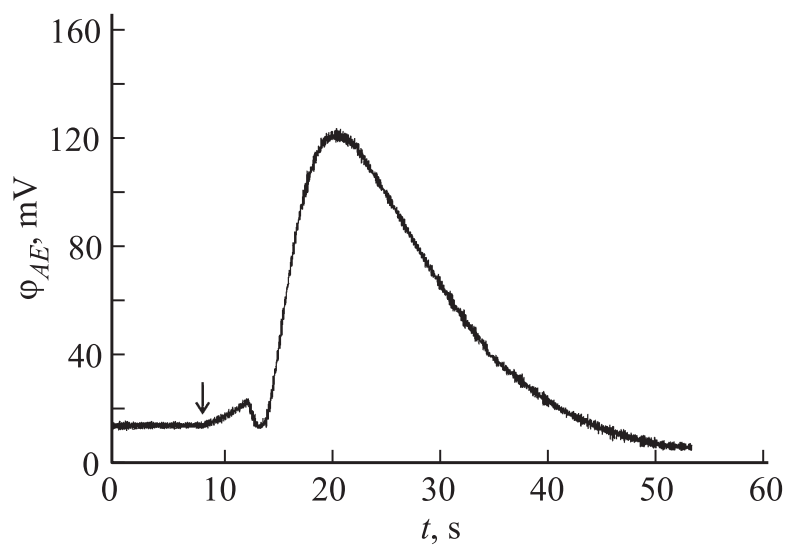

Рис. 2. Сигнал $A E \varphi_{A E}$ после нанесения капли $30 \%$-го раствора $\mathrm{HCl}$ на поверхность недеформированного сплава АМг6. Момент нанесения капли отмечен стрелкой.

кислоты на поверхность недеформированного образца АМг6. Каплю раствора $\mathrm{HCl}$ наносили с помощью шприца. Типичный акустический сигнал $\varphi_{A E}$, показанный на рис. 2, имеет два последовательных колоколообразных скачка: маленький, амплитудой около $5 \mathrm{mV}$ и длительностью около $3 \mathrm{~s}$ и последующий за ним сигнал амплитудой до $\sim 100 \mathrm{mV}$ с длительностью переднего фронта 5-6s и временем спада около $30 \mathrm{~s}$. Процесс растворения алюминиевого сплава сопровождался заметным шипением, связанным с выделением пузырьков водорода в соответствие с уравнением химической реакции. Поэтому регистрируемый сигнал АЭ представляет собой низкочастотную огибающую более высокочастотных акустических событий, связанных с выделением водорода в ходе химической реакции. Отметим, что в результате травления поверхность образца становится матовой, а толщина образца в результате травления уменьшается не более чем на $\sim 1 \mu \mathrm{m}$. Характерная (фрактальная) морфология фронта травления показана на рис. 3, a. Для выполнения фрактального анализа сначала выделяли контур травления с помощью оригинальной компьютерной программы обработки изображения, использующей MatLab и пакет Image Processing [37]. Контур травления определялся как геометрическое место точек максимального градиента уровня яркости полутонового изображения картины травления на рис. 3, $a$. Фрагмент контура травления показан на рис. $3, b$. Затем вычисляли фрактальную размерность $D$ (размерность Хаусдорфа-Безиковича) по формуле [38]

$$
N(\varepsilon) \sim \varepsilon^{-D},
$$

где $N(\varepsilon)$ - минимальное количество квадратов со стороной $\varepsilon$, покрывающих данный контур. На рис. 3, представлена зависимость $N(\varepsilon)$ в двойных логарифмических координатах. Наклон линейной аппроксимации этой зависимости дает значение фрактальной размерности $D=1.32 \pm 0.02$.

На втором этапе плоские оттоженные образцы сплава АМг6 размерами рабочей части $6 \times 3 \times 0.5 \mathrm{~mm}$ растягивали в горизонтальной мягкой деформационной машине со скоростью возрастания напряжения $\dot{\sigma}_{0}=0.3 \mathrm{MPa} / \mathrm{s}$ до ступенчатого участка кривой деформации. По формуле $\Delta t=\Delta \sigma / \dot{\sigma}_{0}$, где величина плато $\Delta \sigma$ связана с амплитудой ступени $\Delta \varepsilon$ выражением (1), оценивали длительность $\Delta t$ очередного плато между ступенями.

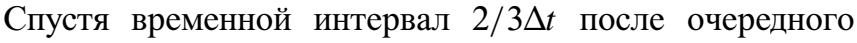
скачка на поверхность образца в центральную область рабочей части образца наносили каплю $30 \mathrm{wt} . \%$-го раствора $\mathrm{HCl}$. Спустя 7-8 s деформируемый образец теряет

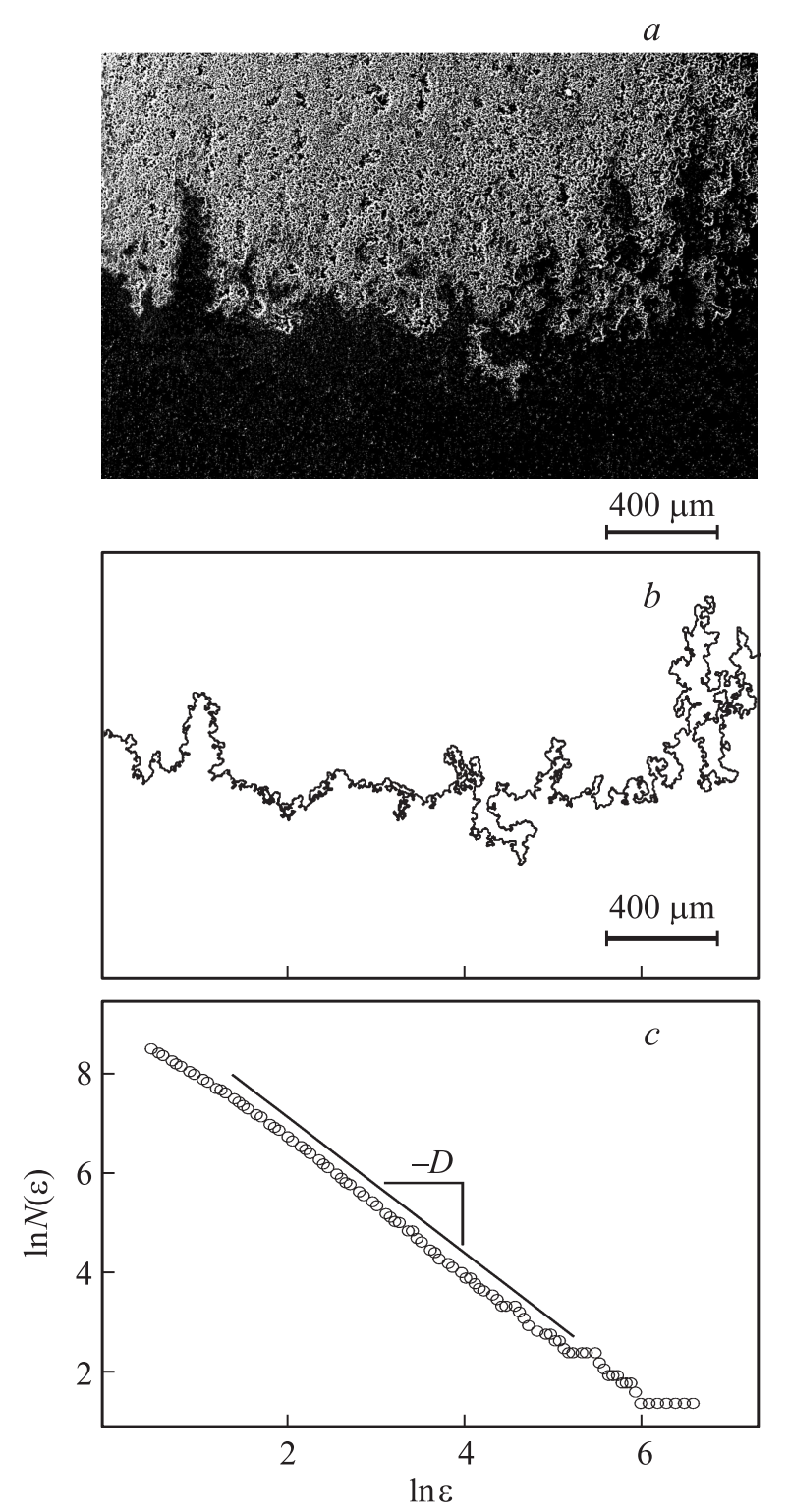

Рис. 3. Результаты компьютерной обработки изображения фронта травления поверхности сплава АМг6 30\%-м раствором $\mathrm{HCl}$. $a-$ фрагмент картины травления, полученный с помощью микроскопа di Innova и обработанный с использованием программы Photoshop; $b-$ контур травления, выделенный компьютерной программой с использованием пакета MatLab; $c$ - зависимость в двойных логарифмических координатах количества $N$ квадратов, покрывающих контур, от стороны квадрата $\varepsilon$. Линейная аппроксимация этой зависимости дает фрактальную размерность $D=1.32 \pm 0.02$. 


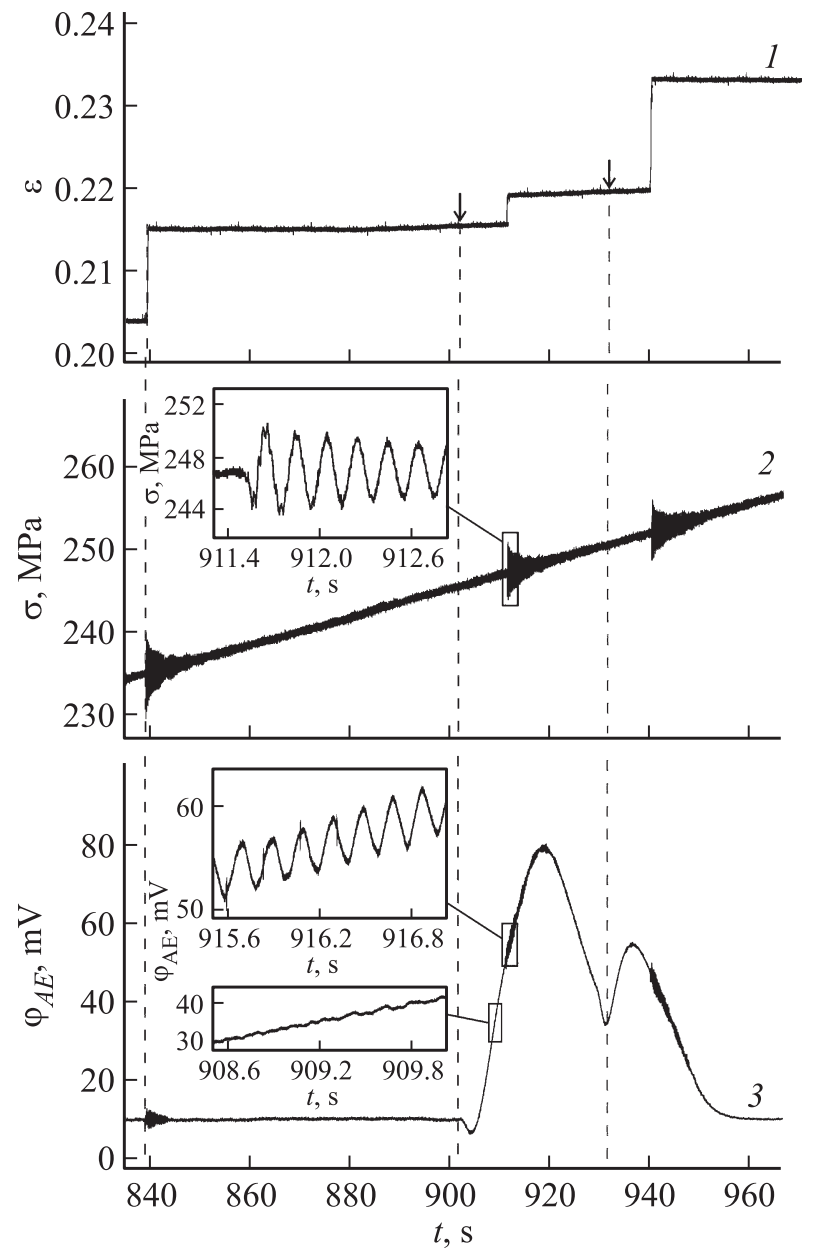

Рис. 4. Синхронная запись деформации $\varepsilon(1)$, силового отклика $\sigma(2)$ и акустического сигнала $\varphi_{A E}(3)$ при нанесении на поверхность деформируемого образца сплава АМг6 30\%-го раствора соляной кислоты. Моменты нанесения двух капель раствора отмечены стрелками. $\dot{\sigma}_{0}=0.3 \mathrm{MPa} / \mathrm{s}, T=300 \mathrm{~K}$.

механическую устойчивость и на поверхности по данным видеосьемки зарождаются и расширяются полосы макролокализованной деформации.

Формирование деформационных полос сопровождается макроскопическим скачком пластической деформации, регистрируемым в виде ступени на кривой нагружения с длительностью переднего фронта около $0.3 \mathrm{~s}$ и амплитудой $1-3 \%$ (рис. 4). Сигнал АЭ также состоит из двух последовательных колоколообразных сигналов, но в отличие от ,холостого опыта“ первый сигнал всегда отрицательный и поэтому его можно рассматривать как предвестник макроскачка пластической деформации. Через 4-5 s на фронте последующего крупного положительного сигнала накладывается более высокочастотный акустический сигнал одновременно с началом скачка деформации и сигналом тензодатчика, регистрирующего вариации усилия в системе машина-образец (см. рис. 4).

Таким образом, экспериментально установлено, что молекулярный (химический) процесс травления поверхности деформируемого алюминиевого сплава вызыва- ет развитие в нем макроскопической дислокационной лавины, создающей скачок пластической деформации амплитудой несколько процентов. Предположительно причина заключается в образовании в ходе травления оптически шероховатой поверхности с разрушенным оксидным слоем и соответственно в возникновении огромного количества хаотично расположенных на поверхности геометрических концентраторов напряжения от субмикроскопического до оптического уровня и соответственно в существенном увеличении количества активных поверхностных дислокационных источников.

3.2. Численно е моделирование процесса формирования фрактальной поверхности в ходе травления поликристаллического твердого тела. Для оценки роли коррозии поверхности в развитии механической неустойчивости рассмотрим эволюцию морфологии фазовой границы при травлении мелкозернистого поликристалла корродирующим раствором конечного объема. В этом случае фрактальная морфология фазовой границы появляется вместе с угасанием химической реакции. Такой тип эволюции обнаружен в экспериментах по коррозии тонкой алюминиевой фольги [39]. В этих экспериментах фрактальная морфология появляется в конце эволюции корродирующей фазовой границы.

Для численного исследования кинетики и морфологии коррозии поверхности сплава, контактирующей с агрессивной средой, рассмотрим простую двумерную модель травления. Следуя [40,41], поликристаллическое твердое тело будем моделировать плотной структурой элементов квадратной формы. Распределение значения прочности этих элементов $w_{1}, w_{2}, \ldots, w_{l}$ по отношению к травлению будем считать хаотичным в пределах от 0 до 1. Обоснованием для такого предположения, является то обстоятельство, что деформируемый алюминиевый сплав представляет собой ультрамелкозернистый поликристалл с приблизительно гауссовым распределением размеров зерна (средний размер зерна около $7 \mu \mathrm{m})$ и случайным распределением фактора Шмида. Кроме того, в области полосы деформации, вследствие интенсивной пластической деформации и выхода на поверхность дислокационных скоплений, можно ожидать образование хаотично распределенных на поверхности микроразрывов окисной пленки, влияющих на интенсивность процесса травления. Начальную активность травления обозначим как $p_{0}=\Gamma C_{0}$, где $C_{0}-$ начальная концентрация травителя, Г - постоянная, которую в дальнейшем примем равной единице [40].

На первом этапе моделирования все позиции на твердой части фазовой границы с $w_{i} \leq p_{0}$ реагируют с травящим веществом и удаляются от фазовой границы. Удаление $n_{i}$ частиц означает, что такое же количество частиц травящего вещества расходуется. Очевидно, что концентрация травящего вещества у фазовой границы истощается и необходима диффузия для доставки молекул травящего вещества к фазовой границе. Однако, если диффузия в жидкости происходит быстро или 

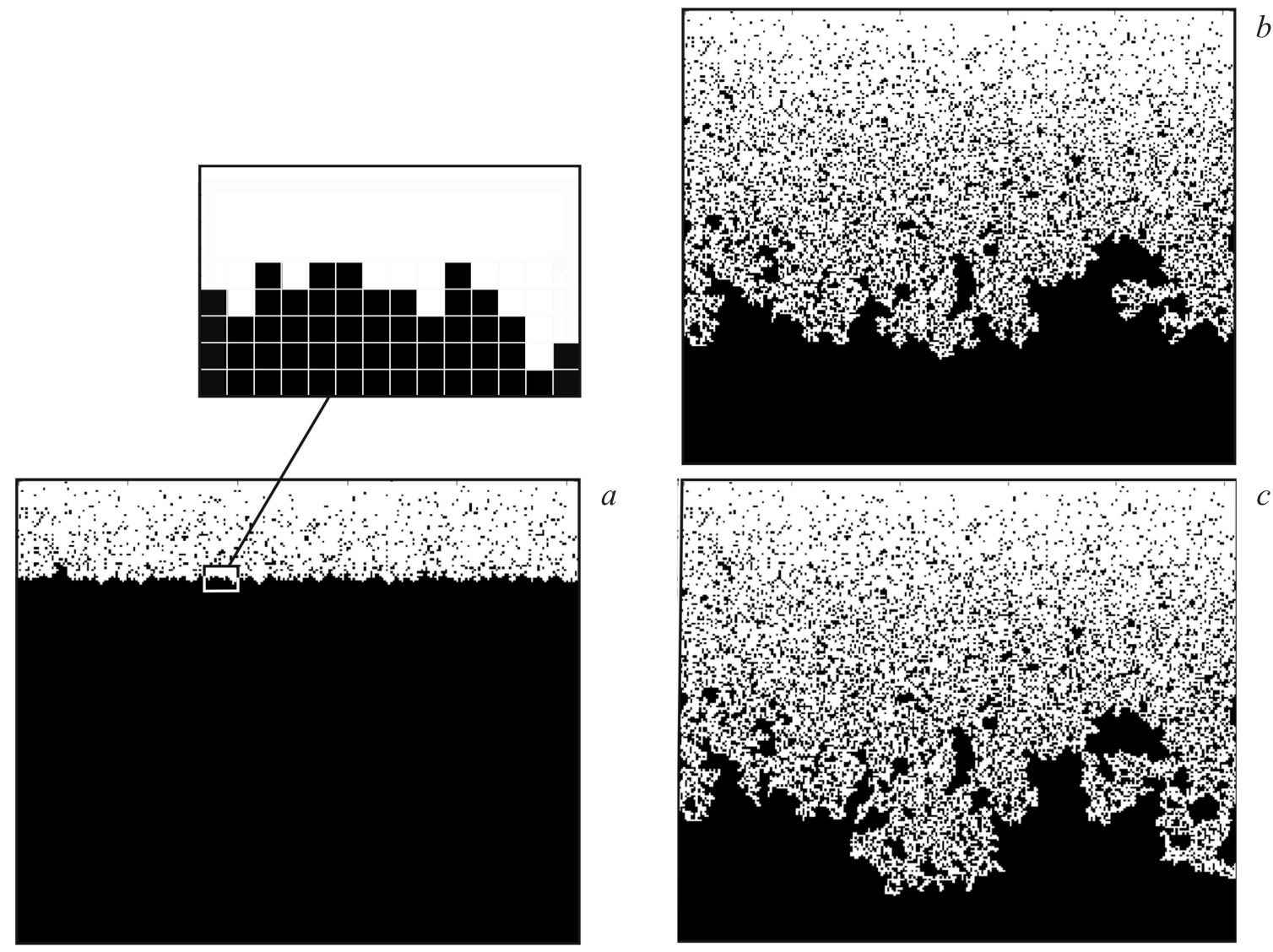

Рис. 5. Результаты численного моделирования на квадратной решетке: временная эволюция фрагмента фазовой границы в различные моменты времени в ходе травления: $t=180(a), t=560(b), t=1132(c)$ - конечная картина. На вставке увеличенный фрагмент фазовой границы - границы раздела твердое тело (плотная структура черных квадратов)-раствор травителя (белое поле). $L=2^{10}, N_{0}=2^{20}$.

коррозия происходит медленно, можно считать, что концентрация раствора травителя остается однородной. Будем пренебрегать также поверхностным натяжением и его влиянием на механические свойства твердого тела, контактирующего с агрессивной средой, т.е. эффектом Ребиндера [42]. В момент времени $t$ количество $n_{i}$ частиц удаляется от фазовой границы, и концентрация раствора соответственно уменьшается $C_{t}=C_{0}-\left(N_{t} / V\right)$, где $N_{t}=\sum_{i=1}^{t} n_{i}-$ суммарное количество частиц, протравленных к моменту времени $t, V$ - объем (здесь площадь) раствора. Интенсивность травления в момент времени $t+1$ дается выражением

$$
p_{t+1}=\Gamma C_{t}=p_{0}\left[1-\left(N_{t} / N_{0}\right)\right],
$$

где $N_{0}=C_{0} V$ - начальное количество молекул травящего вещества. Физическими параметрами, которые управляют процессом травления, при заданном распределении $w_{i}$ являются величины $p_{0}$ и $N_{0}$.

Основные результаты численного моделирования представлены на рис. 5-7. Морфологии фазовой границы в разные моменты времени показаны на рис. 5.
Черные клетки - частицы твердого тела (зерна поликристалла), а белое поле представляет раствор травителя (см. вставку на рис. 5, $a$ ). Видно, что с течением времени происходит переход от евклидовой (гладкой) к фрактальной (шероховатой) морфологии. Следует отметить, что этот процесс спонтанно останавливается через конечное время. Конечная морфология, показанная на рис. 5, c, представляет собой фрактал.

В терминах теории перколяции [43] раствор травит поверхностные позиции кластеров, соответствующих интенсивности травления $p_{t}$ в момент времени $t$. Для исследования временной эволюции системы вычислялись количество протравленных твердых частиц $N_{t}$, значение $p_{t}$ в соответствии с уравнением (3) и средняя глубина травления $\left\langle x_{t}\right\rangle$

$$
\left\langle x_{t}\right\rangle=\frac{1}{n_{s}(t)} \sum_{s=1}^{n_{s}(t)} x_{s}(t),
$$

где $x_{s}(t)$ и $n_{s}(t)$ - координата и полное число позиций на поверхности в момент времени $t$. Для исследования динамики фазовой границы рассчитывалась ее скорость как изменение средней координаты: $v_{t}=\left\langle x_{t+1}\right\rangle-\left\langle x_{t}\right\rangle$. 
Данные были получены для твердого тела шириной $L=2^{10}$ в виде квадратной решетки с $p_{0}=1$ и $N_{0}=2^{20}$. На рис. 6 скорость фазовой границы показана как функция времени. Временная зависимость $v_{t}$, как видно, имеет три характерные области. В начале, в области I, скорость фазовой границы $v_{t}$ почти постоянна. В этом режиме $p_{t}>p_{c}$, где $p_{c} \approx 0.59[38]-$ порог протекания для квадратной решетки. В ходе травления поверхность твердого тела становится шероховатой, но в среднем остается преимущественно плоской (рис. $5, a$ ).

С течением времени, интенсивность травления $p_{t}$ уменьшается и становится сопоставимой с порогом протекания $p_{c}$. Система входит в „критический режим“, в котором скорость фазовой границы постепенно уменьшается, вместе с ней падает и темп травления (область II на рис. 6). Типичная морфология межфазной границы в этом режиме показана на рис. $5, b$. Когда $p_{t}$ лишь незначительно превышает порог протекания $p_{c}$, начинают образовываться конечные кластеры, размеры которых уменьшаются со временем. Для этих кластеров процесс останавливается через конечное время. Последующее резкое уменьшение скорости травления обусловлено тем, что интенсивность травления раствора $p_{t}$ становится меньше, чем $p_{c}$. Наконец, в области III на рис. 5 возникает очень медленный режим, когда скорость фазовой границы $v_{t}$ стремится к нулю. В это время система достигает квазиравновесной морфологии, которая оказывается фрактальной (рис. 5, c).

Как видно из результатов численного моделирования, фрактальная морфология появляется одновременно с замедлением процесса травления, когда $v_{t}$ стремится к нулю. В конце процесса раствор достигает равновесной концентрации $C \leq p_{c} / \Gamma$. Процесс формирования фрактальной границы раздела останавливается за конечное время, поскольку объем и химический потенциал раствора конечны, что отличает этот процесс от обычного фрактального роста типа диффузионной агрегации

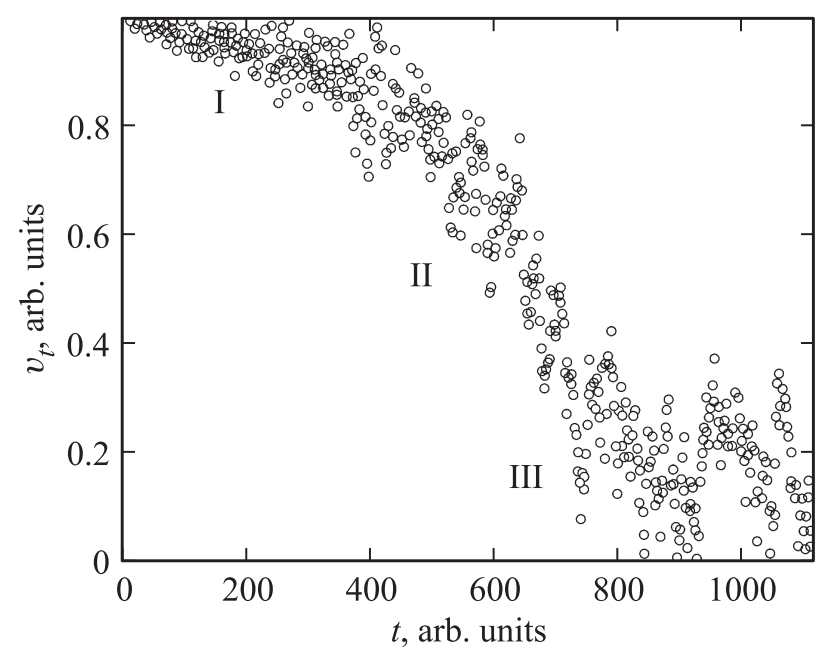

Рис. 6. Скорость фазовой границы $v_{t}$ как функция времени $t$. Наблюдаются три последовательных временных режима, отмеченные римскими цифрами.

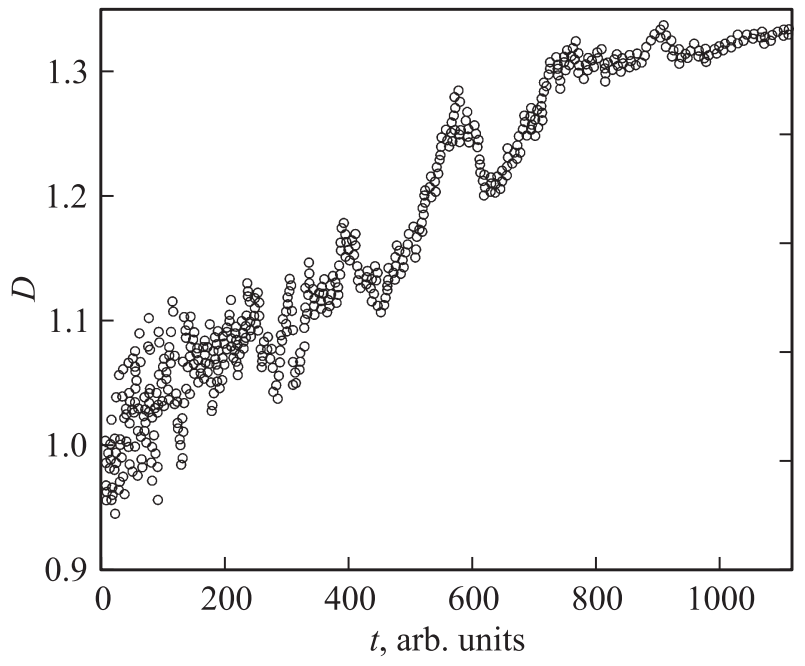

Рис. 7. Эволюция фрактальной размерности $D$ фазовой границы в ходе травления.

частиц [44], перколяции вытеснения [38], дендритной кристаллизации $[45,46]$ и самоорганизующейся критичности [47].

Временная зависимость фрактальной размерности $D$ фазовой границы представлена на рис. 7. В самом начале размерность близка к единице, так как фазовая граница остается еще плоской (евклидова форма). Затем следует рост, связанный с возникающей шероховатостью границы. В конце, когда интенсивность травления $p_{t}$ становится меньше $p_{c}$, фрактальная размерность фазовой границы претерпевает лишь незначительные изменения. Вычисления показывают, что фрактальная размерность конечной фазовой границы равна $D=1.33 \pm 0.10$, что с одной стороны, совпадает с размерностью фронта градиентной перколяции, равной 4/3 [40], а с другой стороны, оказывается близкой к размерности реального фронта травления $D=1.32 \pm 0.02$ (см. рис. $3, c$ ).

Таким образом, с помощью численного моделирования коррозии поликристаллического твердого тела травителем конечного объема, показано, что фазовая граница „твердое тело-жидкость“ становится фрактальной одновременно с замедлением химической реакции. Реакция останавливается полностью за конечное время. Фрактальная размерность конечной фазовой границы оказывается равной размерности фронта градиентной перколяции.

\section{4. Заключение}

В настоящей работе впервые исследовалась связь между коррозией под напряжением и эффектом Портевена-Ле Шателье на примере алюминий-магниевого сплава АМг6. Основные результаты, полученные в работе, состоят в следующем.

1. Экспериментально исследовали влияние агрессивной среды, 30 wt.\% раствора $\mathrm{HCl}$, на механическую 
устойчивость сплава АМг6. Установлено, что через временной интервал $\sim 10$ s после нанесения на поверхность капли раствора образец, деформируемый с постоянной скоростью роста напряжения $\dot{\sigma}_{0}=0.3 \mathrm{MPa} / \mathrm{s}$, теряет механическую устойчивость и на кривой растяжения возникает деформационная ступень амплитудой 1-3\%, которая сопровождается осцилляциями в силовом отклике и характерным акустическим сигналом.

2. Оптические наблюдения и также численное моделирование показывают, что в ходе травления поверхность сплава становится шероховатой (фрактальной), причем вследствие конечности объема травителя процесс спонтанно затухает с формированием конечной фрактальной морфологии с размерностью, равной размерности фронта градиентной перколяции.

3. Предполагается, что в ходе коррозии под напряжением образующаяся фрактальная поверхность сплава создает широкий спектр хаотично распределенных концентраторов напряжения, которые на определенном участке деформационной кривой способствуют развитию макроскопической дислокационной лавины и, соответственно, появлению скачка деформации амплитудой несколько процентов. Полученные результаты подтверждают важную роль состояния поверхности на развитие макроскопической пластической неустойчивости сплава, демонстрирующего эффект ПЛШ.

Необходимы дальнейшие исследования влияния коррозии под напряжением на прерывистую деформацию и полосообразование алюминиевых авиационных сплавов, включающие учет диффузионных процессов в объеме травителя и вдоль фазовой границы, роль вариации поверхностного натяжения, а также микроструктурные исследования поверхности для верификации результатов численного моделирования процесса коррозии.

\section{Список литературы}

[1] Дж.Ф. Белл. Экспериментальные основы механики деформируемых твердых тел. Ч. 2. Наука, М. (1984) 432 с.

[2] M. Reboul, B. Baroux. Mater. Corros. 62, 215 (2011).

[3] E. Sikora, X. Wei, B. Shaw. Corros. Sci. 60, 387 (2004).

[4] M.M. Sharma, C.W. Ziemian. J. Mater. Eng. Perform. 17, 870 (2008).

[5] J.C. Chang, T.H. Chuang. Metall. Mater. Trans. A 30, 3192 (1999).

[6] N. Winzer, A. Atrens, W. Dietzel, V.S. Raja, G. Songe, K.U. Kainer. Mater. Sci. Eng. A 488, 339 (2006).

[7] R. Jones, D. Baer, M. Danielson, J. Vetremo. Metall. Mater. Trans. A 32, 1699 (2001).

[8] M. Popovic, E. Romhanji. J. Mater. Progress. Technol. 125-126, 275 (2002).

[9] J. Chang, T. Chuang. Metall. Mater. Trans. A 30, 3191 (1999).

[10] R. Goswami, G. Spanos, P.S. Pao, R.L. Holts. Metall. Mater. Trans. A 42, 348 (2010).

[11] R.A. Jones, Y.Y. Gertsman, J.S. Vetrano, C.F. Windisch. Scr. Mater. 50, 1355 (2004).

[12] J. Pickens, J. Gordon, J.A.S. Green. Metall. Mater. Trans. A 14, 925 (1983)

[13] R.H. Jones. JOM. 55, 42 (2003).
[14] H. Yukama, Y. Murata, M. Morinaga, Y. Takahashi, H. Yoshida. Acta Metall. Mater. 43, 681 (1995).

[15] J.L. Searles, P.I. Gouma, R.G. Buchheit. Metall. Mater. Trans. A 32, 2859 (2001).

[16] G.R. Argade, N. Kumar, R.S. Mishra. Mat. Sci. Eng. A 565, 80 (2013).

[17] C. Vargel. Corrosion of aluminium. Elsevier Ltd., Oxford (2004). 658 p.

[18] P.R. Swann, H.W. Pickering. Corosion. 19, 369t (1963).

[19] A.H. Cottrell. Phil. Mag. 44, 89 (1953).

[20] Y. Estrin, L.P. Kubin / Continuum models for materials with microstructure. Ed. H.-B. Muhlhaus. Wiley \& Sons, N.Y. (1995). P. 395.

[21] A. Van den Beukel. Phys. Status. Solidi A 30, 197 (1975).

[22] M.M. Sharma, J.D. Tomedi, T.J. Weigly. Mater. Sci. Eng. A 619, 35 (2014).

[23] А.А. Шибков, М.А. Желтов, М.А. Лебедкин, В.В. Скворцов, Р.Ю. Кольцов, А.В. Шуклинов. Заводская лаборатория 71, 20 (2005).

[24] А.А. Шибков, А.Е. Золотов, М.А. Желтов, А.А. Денисов, М.Ф. Гасанов. ФТТ 56, 40 (2014).

[25] А.Т. Златкин, Э.Л. Лубе, И.Н. Циглер, К.П. Чиркина. Кристаллография 34, 1579 (1989).

[26] М.М. Криштал, Д.Л. Мерсон. ФММ 10, 187 (1991).

[27] М.М. Криштал, Д.Л. Мерсон. ФММ 81, 156 (1996).

[28] М.М. Криштал, А.К. Хрусталев, А.А. Разуваев, И.С. Демин. Деформация и разрушение материалов 1, 28 (2008).

[29] А.А. Шибков, А.Е. Золотов, М.А. Желтов. ФТТ 52, 2223 (2010).

[30] А.А. Шибков, А.Е. Золотов. Кристаллография 56, 147 (2011).

[31] А.А. Шибков, М.А. Желтов, А.А. Королев. Природа 9, 12 (2000).

[32] А.А. Шибков, С.А. Титов, М.А. Желтов, М.Ф. Гасанов, А.Е. Золотов, К.А. Проскуряков, А.О. Жигачев. ФТТ 58, 3 (2016).

[33] G.F. Xiang, Q.C. Zhang, H.W. Lin, X.P. Wu, X.Y. Ju. Scr. Mater. 56, 721 (2007).

[34] W. Tong, H. Tao, N. Zhang, L.G. Hector Jr. Scr. Mater. 53, 87 (2005).

[35] А.А. Шибков, А.Е. Золотов, М.А. Желтов. Изв. РАН. Сер. физ. 76, 97 (2012).

[36] А.А. Шибков, А.Е. Золотов, Д.В. Михлик, М.А. Желтов, А.В. Шуклинов. Деформация и разрушение материалов 9, $22(2009)$.

[37] R.C. Gonzalez, R.E. Woods. Digital Image Processing, 2 nd ed. Prentice Hall, Upper Saddle River, N. Y. (2002) 609 p.

[38] Е. Федер. Фракталы. Мир, М. (1991). 230 с.

[39] L. Balazs. Phys. Rev. 54, 1183 (1996).

[40] B. Sapoval, S.B. Santra, Ph. Barboux. Europhys. Lett. 41, 297 (1998).

[41] A. Gabrielli, A. Baldassarri, B. Sapoval. Phys. Rev. 62, 3103 (2008).

[42] Н.А. Ребиндер, Е.Д. Щукин. УФН 108, 3 (1972).

[43] Ю.Ю. Тарасевич. Перколяция: теория, приложения, алгоритмы. Либроком, М. (2012). 112 с.

[44] T.A. Witten, L.M. Sander. Phys. Rev. Lett. 27, 5686 (1983).

[45] T. Abel, E. Brener, H. Müller-Krumbhaar. Phys. Rev. E 55, 7789 (1997).

[46] А.А. Шибков, Ю.И. Головин, М.А. Желтов, А.А. Королев, А.А. Власов. Кристаллография. 46, 549 (2001).

[47] P. Bak, C. Tang, K. Wiessenfeld. Phys. Rev. A 38, 364 (1988). 